\title{
Effect of melting rate on microsegregation and primary MC carbides in M2 high-speed steel during electroslag remelting
}

\author{
Fu-xing Yin ${ }^{1,2}$, Ming Sü ${ }^{1,2}$, Fa Ji, ${ }^{1,2}$, Qing-chao Tian ${ }^{3}$, Ya-guan Bai ${ }^{4}$, Jian-hang Feng ${ }^{1,2}$, *Zhi-xia Xiao ${ }^{1,2}$ \\ 1. School of Materials Science and Engineering, Hebei University of Technology, Tianjin 300130, China \\ 2. Tianjin Key Laboratory of Layered Composite Materials, Tianjin 300130, China \\ 3. State Key Laboratory of Advanced Special Steel, Shanghai Key Laboratory of Advanced Ferrometallurgy, School of Materials Science \\ and Engineering, Shanghai University, Shanghai 200444, China \\ 4. Tianjin Heavy Industries Research and Development Co., Ltd., Tianjin 300457, China
}

\begin{abstract}
Large-size primary MC carbides can significantly reduce the performance of M2 high-speed steel. To better control the morphology and size of primary MC carbides, the effect of melting rate on microsegregation and primary $\mathrm{MC}$ carbides of $\mathrm{M} 2$ steel during electroslag remelting was investigated. When the melting rate is decreased from $2 \mathrm{~kg} \cdot \mathrm{min}^{-1}$ to $0.8 \mathrm{~kg} \cdot \mathrm{min}^{-1}$, the columnar dendrites are gradually coarsened, and the extent of segregation of $\mathrm{Mo}$ and $\mathrm{V}$ is alleviated, while the segregation of $\mathrm{Cr}$ becomes severe. At $2 \mathrm{~kg} \cdot \mathrm{min}^{-1}$, the number of primary MC carbides per unit area with the sizes in the range of $2 \mu \mathrm{m}$ to $6 \mu \mathrm{m}$ accounts for about $75 \%$ of all MC carbides, while the carbides are mainly concentrated on the size larger than $8 \mu \mathrm{m}$ at $0.8 \mathrm{~kg} \cdot \mathrm{min}^{-1}$. Thermodynamic calculations based on the Clyne-Kurz (simplified to $\mathrm{C}-\mathrm{K}$ ) model shows that $\mathrm{MC}$ carbide can be precipitated in the final solidification stage and a smaller secondary dendrite arm spacing caused by higher melting rate $\left(2 \mathrm{~kg} \cdot \mathrm{min}^{-1}\right.$ in this experiment) facilitates the refinement of primary MC carbides.
\end{abstract}

Key words: high-speed steel; MC carbide; melting rate; electroslag remelting; microsegregation

CLC numbers: TG142.45 Document code: A Article ID: 1672-6421(2021)03-163-07

\section{Introduction}

High-speed steels (HSSs) are widely used in making cutting tools due to their high hardness and good wear resistance even at high temperature. These excellent properties can be attributed to the carbides uniformly distributed in the matrix, such as $\mathrm{MC}, \mathrm{M}_{6} \mathrm{C}$, etc ${ }^{[1,2]}$. As for W-Mo HSSs, the as-cast structure at room temperature mainly contains $\mathrm{M}_{2} \mathrm{C}$ eutectic carbides and a small number of large-size primary $\mathrm{MC}$ carbides (stable phase) directly precipitate from the liquid phase ${ }^{[3]}$. Among them, $\mathrm{M}_{2} \mathrm{C}$ is a metastable phase, and could totally decompose into smaller $\mathrm{MC}$ and $\mathrm{M}_{6} \mathrm{C}$ secondary carbides after a series of processing ${ }^{[4-6]}$. Even though MC carbides have the highest hardness (around $3,000 \mathrm{HV}$ ) and contribute high wear resistance ${ }^{[7]}$, these

\section{*Zhi-xia Xiao}

Famale, born in 1984, Ph. D, Senior Engineer. Her research interests mainly focus on the electroslag remelting process, the design and manufacturing of high performance steels.

E-mail: hbgdxzx@163.com

Received: 2020-11-13; Accepted: 2021-04-29 primary MC carbides are large in size and irregular in shape, and are detrimental to the fracture toughness of HSSs $^{[8]}$. Furthermore, they consume a large amount of carbon and other alloy elements in the matrix, which leads to a reduction in the strength and toughness of the steel. Therefore, controlling the morphology and size of primary $\mathrm{MC}$ carbides is very important to improve the performance of HSSs.

Many efforts have been made to refine primary carbides. One effort is the mechanical processing (forging or rolling) combined with heat treatment method. This is a traditional method for refining austenite grain and improving secondary precipitation of carbides in HSSs ${ }^{[9]}$. Ghomashchi et al. ${ }^{[10]}$ found that $\mathrm{M}_{6} \mathrm{C}$ eutectic carbide was fragmented and spheroidized after hot forging and post deformation, while MC carbide remained mainly unchanged in morphology, but a little coarsening in size under the same deformation condition. This implies that a greater amount of deformation is required to break up the primary MC carbide, which is usually difficult to achieve in the core of the ingot. More seriously, the size of primary MC carbide in the core is usually the largest. 
Another effort is a microalloying and modification method. Dobrzański et al. ${ }^{[11,12]}$ found that the austenite grain size in W-Mo-V HSSs was decreased obviously through the addition of $\mathrm{Ti}$ or $\mathrm{Nb}$ as partial substitutions for some expensive alloy elements (such as Mo, V and W). However, $\mathrm{Nb}$ and $\mathrm{Ti}$ accelerated the formation of coarse MC primary carbides. Ding et al. ${ }^{[3]}$ illustrated that increasing V would cause the change of eutectic carbide from a harmful skeletal morphology $\left(\mathrm{M}_{6} \mathrm{C}\right.$ carbides $)$ to a lamellar morphology (unstable $\mathrm{M}_{2} \mathrm{C}$ carbides). This not only enhanced the formation of $\mathrm{M}_{2} \mathrm{C}$ carbides, but also accelerated the formation of primary $\mathrm{MC}$ carbides. Li et al. ${ }^{[13]}$ refined the eutectic and network MC by adding RE-Al-B-Ti. Fu et al. ${ }^{[14]}$ modified M2 cast HSS by adding RE-Al-N to eliminate the network eutectic carbides. However, unless the addition process is effectively controlled, the addition of these rare earths and their composites may introduce undesirable inclusions.

As far as we know, the most effective method to control carbides is to increase the cooling rate to reduce elemental segregation and modify the carbides ${ }^{[15-17]}$. Electroslag remelting (ESR), which has a strong cooling rate by the use of watercooled copper mold, is considered to be effective in controlling segregation ${ }^{[18]}$. Among all ESR process parameters, melting rate significantly affects the molten-metal pool shape and the structure after solidification. Chen et al. ${ }^{[19]}$ simulated the influence of the melting rate on the depth of the molten-metal pool and grain growth angle during ESR process, and obtained the most suitable melting rate to control the solidified structure of Mn18Cr18N hollow ingot. Zhu et al. ${ }^{[20]}$ demonstrated that primary carbides of $\mathrm{M}_{7} \mathrm{C}_{3}$ in $8 \mathrm{Cr} 13 \mathrm{MoV}$ stainless steel were refined and their amount was reduced when using a lower ESR melting rate. Since the relationship between melting rate and local solidification time (that is the time the alloy stays in the mushy zone, simplified to LST) is not monotonic ${ }^{[18]}$, the influence of the melting rate on the solidification structure becomes more complicated. This makes it difficult to predict the optimal melting rate to achieve the best microstructure. Moreover, the effect of melting rate on primary MC carbides needs to be further studied.

In this study, the dendritic structure and element segregation of M2 HSS after ESR with three melting rates were analyzed. The morphology, distribution and size of primary MC carbides at different melting rates were compared, and the effect of melting rate on the precipitation mechanism of MC carbides was investigated using thermodynamic theory coupled with Clyne-Kurz (simplified to C-K) segregation model.

\section{Experimental procedure}

ESR experiment was completed in a fully enclosed chamber and argon gas was introduced to control the oxygen content of the chamber during the remelting process. The M2 alloy rods with a diameter of $100 \mathrm{~mm}$ and a length of $800 \mathrm{~mm}$ were purchased and used as the ESR electrodes. The chemical composition of the electrode measured by ICP-AES method was 0.78wt.\% C, 0.28wt.\% Si, 0.31wt.\% Mn, 3.94wt.\% Mo, 5.68wt.\% W, 3.68wt.\% Cr, 1.82wt.\% V, 0.0873wt.\% Al, and $\mathrm{Fe}$ in balance. The different melting rates were achieved by the melting rate control module of the ESR equipment, which was designed by Shenyang Huasheng Metallurgical Technology and Equipment Co., Ltd. In this study, the melting rate of the ESR ingot was set to $2,1.2$ and $0.8 \mathrm{~kg} \cdot \mathrm{min}^{-1}$, respectively. The inlet and outlet temperatures of the mold cooling water were maintained at about $298 \mathrm{~K}\left(25^{\circ} \mathrm{C}\right)$ and $308 \mathrm{~K}\left(35^{\circ} \mathrm{C}\right)$ during the ESR process, respectively.

The samples were firstly taken from the center of the ESR ingot when the solidification reached a steady state at a constant melting rate. Then they were mechanically polished and etched using a Murakami etchant $3 \mathrm{~g} \mathrm{~K}_{3} \mathrm{Fe}(\mathrm{CN})_{6}+$ $\left.10 \mathrm{~g} \mathrm{NaOH}+100 \mathrm{~mL} \mathrm{H}_{2} \mathrm{O}\right]$. The dendritic structure was analyzed using an optical microscope (OM). The value of secondary dendrite arm spacing (SDAS) was calculated by dividing the selected length by the numbers of intersected secondary arms. The mean value of SDAS was calculated from 30 measurements per sample. Element segregation and morphology of the primary carbides were carried out by JXA$8530 \mathrm{~F}$ electron probe microanalyses (EPMA). The types of carbides were confirmed using a SmartLab $90 \mathrm{~kW}$ intelligent $\mathrm{X}$-ray diffractometer. The content of the primary MC carbides was quantitatively analyzed using secondary electron images. The number of MC carbides with different sizes was summed after observing 30 fields with a magnification of 500 times. The dimensions of these polygonal carbides were measured according to their longest diagonal.

\section{Results and discussion}

\subsection{Dendritic structure and element segregation}

Figure 1 compares the structure of M2 ingot with different melting rates. As shown in Fig. 1(a), some fine columnar dendrites mixed with a small amount of equiaxed dendritic structures are observed at melting rate of $2 \mathrm{~kg} \cdot \mathrm{min}^{-1}$. The content of equiaxial dendrites is about $5 \%$ as measured from two-dimensional observations. When the melting rate decreases to $1.2 \mathrm{~kg} \cdot \mathrm{min}^{-1}$, as seen in Fig. 1(b), columnar dendrites are slightly thickened and the content of equiaxed dendrites increases to about $7 \%$. In further decreasing the melting rate to $0.8 \mathrm{~kg} \cdot \mathrm{min}^{-1}$, columnar dendrites are further coarsened as shown in Fig. 1(c), and the content of equiaxed dendrites goes up to about $10 \%$. Measurements show that the SDAS is increased from about $50 \mu \mathrm{m}$ to $70 \mu \mathrm{m}$ as the melting rate is decreased from $2 \mathrm{~kg} \cdot \mathrm{min}^{-1}$ to $0.8 \mathrm{~kg} \cdot \mathrm{min}^{-1}$.

According to the results of Fischmeister ${ }^{[21]}$, in M2 alloy, the empirical relationship between SDAS $\left(d_{\mathrm{II}}\right)$ and cooling rate $\left(R_{\mathrm{C}}\right)$ or $\operatorname{LST}\left(t_{\mathrm{f}}\right)$ is represented by Eq. (1) or Eq. (2), respectively. Based on these equations, it can be inferred from the increase of SDAS in the experiment that the cooling rate becomes smaller or LST becomes longer. However, for the ESR process, the melting rate has a complicated relation with some solidification 
parameters, such as solidification rate (the velocity of the solidification front, $V_{\mathrm{r}}$ ), cooling rate, or LST. Mitchell and Hernandez-Morales et al. ${ }^{[22,23]}$ indicated that increasing the melting rate would result in the increase of solidification rate and the decrease of temperature gradient $(G)$. If the solidification rate is dominant, increasing the melting rate will lead to an increase in cooling rate according to Eq. (3), and a decrease in LST, while if the temperature gradient is dominant, the changes of cooling rate and the LST are just the opposite.
In this experiment, it is inferred that when the melting rate is decreased from $2 \mathrm{~kg} \cdot \mathrm{min}^{-1}$ to $0.8 \mathrm{~kg} \cdot \mathrm{min}^{-1}$, the solidification rate is dominant. Therefore, it would result in a decrease in cooling rate and an increase in SDAS with the decrease of melting rate.

$$
\begin{gathered}
d_{\mathrm{II}}=b R_{\mathrm{c}}^{-\mathrm{n}}\left(30.6 \mu \mathrm{m} \cdot \mathrm{s} \cdot \mathrm{K}^{-1}<b<47.4 \mu \mathrm{m} \cdot \mathrm{s} \cdot \mathrm{K}^{-1}, 0.34<n<0.38\right) \\
d_{\mathrm{II}}=5 t_{\mathrm{f}}^{0.38} \\
R_{\mathrm{c}}=G V_{\mathrm{r}}
\end{gathered}
$$
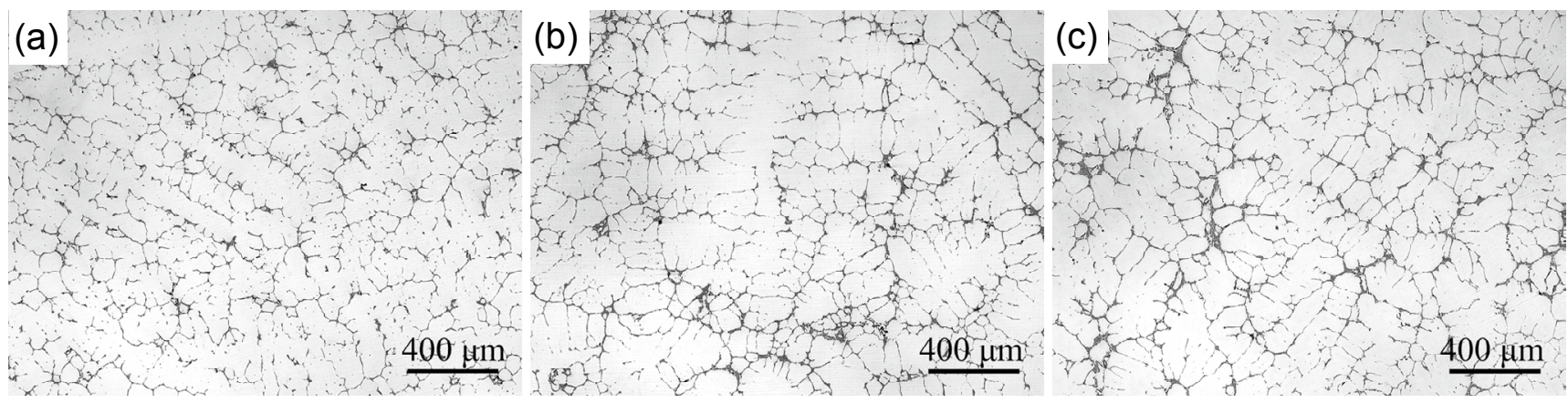

Fig. 1: Optical micrograph of M2 alloy at melting rates of $2 \mathrm{~kg} \cdot \mathrm{min}^{-1}$ (a), $1.2 \mathrm{~kg} \cdot \mathrm{min}^{-1}$ (b), and $0.8 \mathrm{~kg} \cdot \mathrm{min}^{-1}$ (c)

The element content of the main alloy elements between the dendrite core $\left(C_{\mathrm{d}}\right)$ and the interdendritic region $\left(C_{\mathrm{i}}\right)$ was determined by EPMA and the statistical results are shown in Fig. 2. Since the equilibrium partition coefficients $(k)$ of solute elements are less than 1 , as listed in Table 1, elements $\mathrm{W}$, $\mathrm{Mo}, \mathrm{Cr}$ and $\mathrm{V}$ tend to segregate into the interdendritic region. Furthermore, the greater the difference in element content between the interdendritic region and dendrite core $\left(\Delta C=C_{\mathrm{i}}-C_{\mathrm{d}}\right)$, the more severe the microsegregation. At the melting rate of $2 \mathrm{~kg} \cdot \mathrm{min}^{-1}$, the extent of segregation of $\mathrm{Mo}$ and $\mathrm{Cr}$ is relatively large, while $\mathrm{V}$ is moderate, and the segregation of $\mathrm{W}$

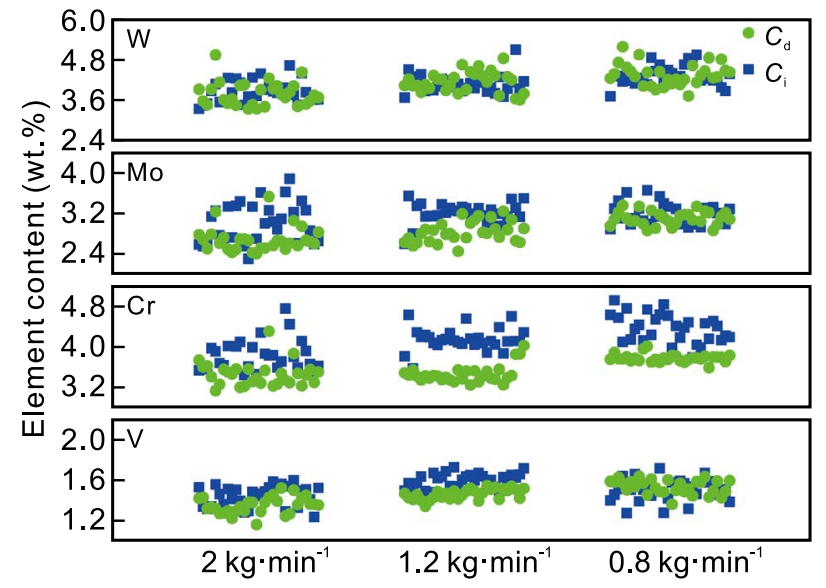

Fig. 2: Element content of main alloy elements between dendrite core $\left(C_{\mathrm{d}}\right)$ and interdendritic $\left(C_{\mathrm{i}}\right)$ region with different melting rates is the weakest. When the melting rate gradually decreases to $0.8 \mathrm{~kg} \cdot \mathrm{min}^{-1}$, the segregation of Mo and $\mathrm{V}$ tends to be alleviated, while the segregation of $\mathrm{Cr}$ becomes severe. There is little change in the segregation of $\mathrm{W}$.

There are mainly three factors that determine the element microsegregation in the ingot, which are solidification path, partition coefficient and diffusion coefficient ${ }^{[24]}$. The solidification path of M2 alloy is $\mathrm{L} \rightarrow \mathrm{L}+\delta \rightarrow \mathrm{L}+\delta+\gamma \rightarrow$ $\mathrm{L}+\gamma+$ carbides $\rightarrow \gamma+$ carbides. In this experiment, the limited change in cooling rate caused by the melting rate would not alter the type of solidified phase of the M2 ingot (as illustrated by Fig. 4, which will be discussed below). Frediksson ${ }^{[25]}$ measured the alloy composition of M7 steel quenched from the melt and the results showed that $\mathrm{W}$ and $\mathrm{Cr}$ were homogeneously distributed throughout the primary $\delta$ dendrite before the start of the peritectic reaction $(\mathrm{L}+\delta \rightarrow \gamma)$. As for the solute elements of Mo and V, due to their higher diffusion coefficients in $\delta$ phase (Fig. 3) ${ }^{[26]}$ and the partition coefficients in $\delta$ phase with little difference compared to those of $\mathrm{W}$ and $\mathrm{Cr}$ (Table 1), their concentration distributions can be considered to be homogeneous along the $\delta$ dendrite. After the peritectic reaction starts, the diffusion speed of the alloying element in $\gamma$ phase plays a dominant role in element segregation. Moreover, the higher the diffusion coefficient of solute element in $\gamma$ phase, the weaker the element segregation in $\gamma$ phase. In further cooling to room temperature, due to the strong cooling caused by the water-cooled copper mold during ESR process,

Table 1: Equilibrium partition coefficients $(k)$ of solute elements between solid ( $\delta$ phase or $y$ phase) and liquid in steel ${ }^{[26]}$

\begin{tabular}{cccccccccc} 
Element & C & Si & Mn & Al & W & Mo & Cr & V \\
\hline$k^{5 / L}$ & 0.19 & 0.77 & 0.77 & 0.6 & 0.85 & 0.8 & 0.95 & 0.93 \\
$k^{\text {VL }}$ & 0.34 & 0.52 & 0.785 & 0.6 & 0.45 & 0.585 & 0.86 & 0.63
\end{tabular}




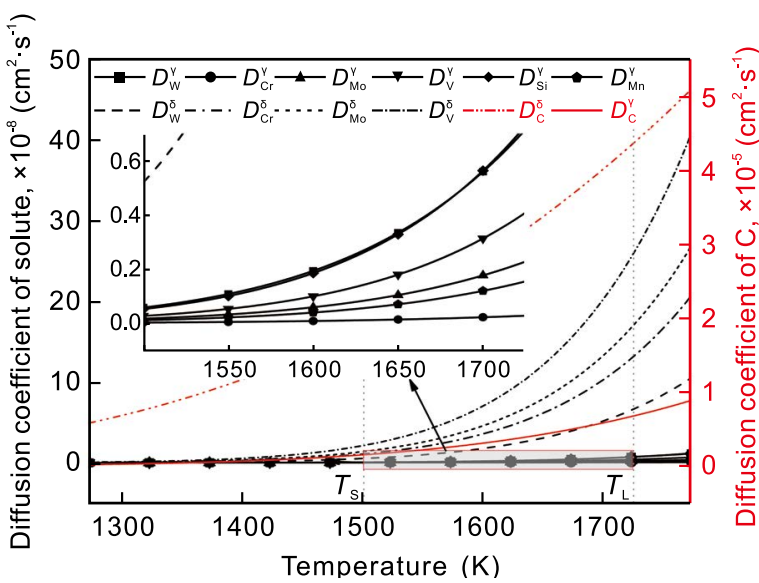

Fig. 3: Diffusion coefficients $(D)$ of some solute elements in $\delta$ phase and $y$ phase of steel ${ }^{[26]}$

the $\gamma$ phase transforms into the non-diffusive martensite phase. Hence, the extent of segregation of the alloying elements in the high-temperature $\gamma$ phase could be retained in the roomtemperature martensite phase. As shown in Fig. 3, W has the highest diffusion coefficient in the high-temperature $\gamma$ phase, so $\mathrm{W}$ segregation is the lightest. In contrast, the diffusion coefficients of $\mathrm{Mo}$ and $\mathrm{Cr}$ are low, and thus their segregation is more severe. Since the cooling rate becomes lower resulting from the decreasing of melting rate, solute elements have more time to diffuse to achieve homogenization. Therefore, as the melting rate is decreased, the segregation of Mo and $\mathrm{V}$ is further alleviated. However, $\mathrm{Cr}$ exhibits an abnormal segregation behavior, which might be because it is usually a comparatively weak ferrite stabilizer, and it may even have a slight tendency to stabilize austenite as indicated by Fredriksson ${ }^{[2]}$.

\subsection{Morphology, distribution and size of MC primary carbides}

Figure 4 shows the XRD spectra of M2 alloy with three melting rates. There are three main phases, which are the matrix phase of $\alpha$-Fe phase and the carbides of $\mathrm{M}_{2} \mathrm{C}$ (hexagonal structure) and $\mathrm{MC}$ (cubic structure). As the melting rate gradually decreases from $2 \mathrm{~kg} \cdot \mathrm{min}^{-1}$ to $0.8 \mathrm{~kg} \cdot \mathrm{min}^{-1}$, the (222) peak intensity and (400) peak intensity of MC significantly drop as seen by the arrows in Fig. 4. This indicates that the relative content of MC carbide of the M2 alloy significantly reduces with the decrease of melting rate.

The number of primary MC carbides per unit area under three melting rates is shown in Fig. 5. At the melting rate of $2 \mathrm{~kg} \cdot \mathrm{min}^{-1}$, the number of primary MC carbides per unit area with the size in the range of $2 \mu \mathrm{m}$ to $6 \mu \mathrm{m}$ accounts for about $75 \%$ of all MC carbides. The number of primary MC carbides per unit area with the size greater than $8 \mu \mathrm{m}$ is the lowest of all sizes. Reducing the melting rate to $1.2 \mathrm{~kg} \cdot \mathrm{min}^{-1}$, the carbides size is mainly concentrated in the range of $4 \mu \mathrm{m}$ to $8 \mu \mathrm{m}$, which accounts for about $65 \%$ of all MC carbides. As the melting rate is further reduced to $0.8 \mathrm{~kg} \cdot \mathrm{min}^{-1}$, the size of carbides is mainly concentrated on larger than $8 \mu \mathrm{m}$, accounting for about $40 \%$ of all sizes. It is apparent that as the

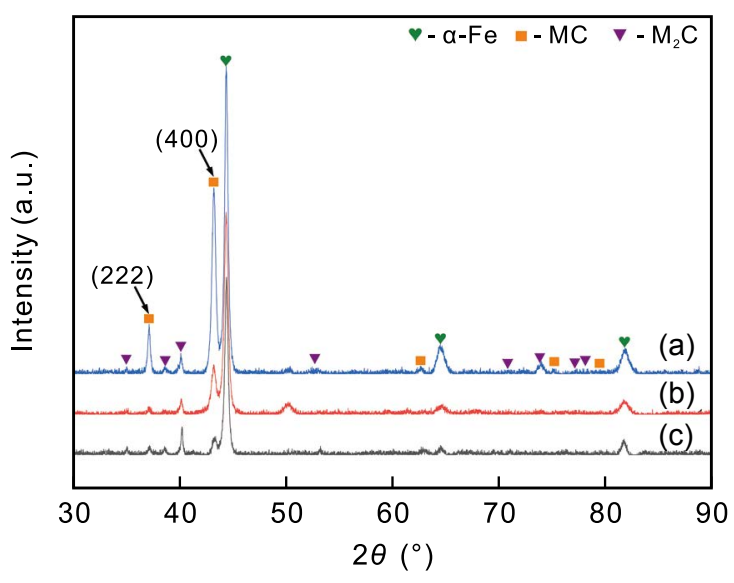

Fig. 4: XRD patterns of M2 alloy with melting rate of $2 \mathrm{~kg} \cdot \mathrm{min}^{-1}(\mathrm{a}), 1.2 \mathrm{~kg} \cdot \mathrm{min}^{-1}(\mathrm{~b})$, and $0.8 \mathrm{~kg} \cdot \mathrm{min}^{-1}$ (c)

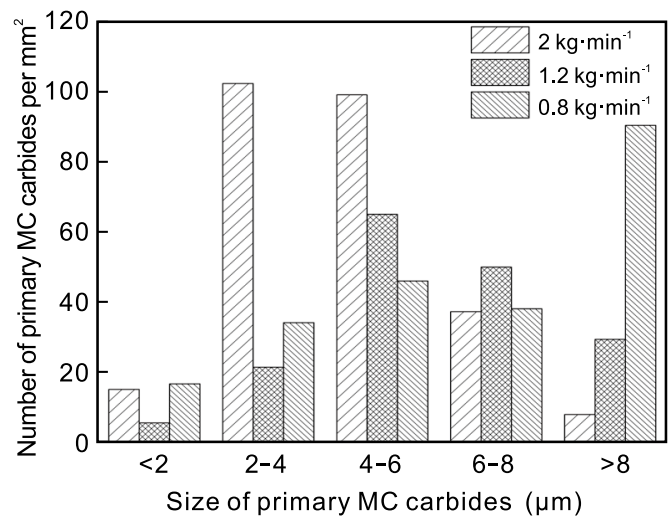

Fig. 5: Number of primary MC carbides per unit area

melting rate is reduced, among the $\mathrm{MC}$ carbides with different sizes, the size of carbides with the greatest number per unit area gradually increases. This indicates to a certain extent that $\mathrm{MC}$ carbides at the melting rate of $2 \mathrm{~kg} \cdot \mathrm{min}^{-1}$ are more refined compared to those at the melting rate of $0.8 \mathrm{~kg} \cdot \mathrm{min}^{-1}$. Meanwhile, the relative content of MC carbides is the largest at $2 \mathrm{~kg} \cdot \mathrm{min}^{-1}$ (Fig. 4), which means that the distribution of MC carbides may be more dispersed. Figure 6 shows the carbides distribution under different melting rates at low magnification. The black spots in Fig. 6 are the primary MC carbides. It is known that precipitation of $\mathrm{MC}$ carbides is promoted and their distribution is more uniform at $2 \mathrm{~kg} \cdot \mathrm{min}^{-1}$.

Figure 7 shows the morphology of MC primary carbides at melting rate of 2, 1.2 and $0.8 \mathrm{~kg} \cdot \mathrm{min}^{-1}$, respectively. The dark gray irregular blocky carbide in Fig. 7 is primary MC. According to the quantitative analysis of EPMA [P1 is represented by the black cross in Fig. 7(a)], it contains up to about $60 \mathrm{wt} . \% \mathrm{~V}$, and dissolves a small amount of $\mathrm{Cr}$, Mo, $\mathrm{W}, \mathrm{Mn}$ and Fe. Attached to the MC carbide is lamellar Morich $\mathrm{M}_{2} \mathrm{C}$ eutectic, as seen by line analysis in Fig. 7(a). As the melting rate is gradually decreased, the blocky MC carbide becomes larger, while the element compositions are almost unchanged as measured by P2 of Fig. 7(b) and P3 of Fig. 7(c). These MC carbides with sizes up to a few microns or even tens of microns indicate that they may precipitate out of the liquid phase. 

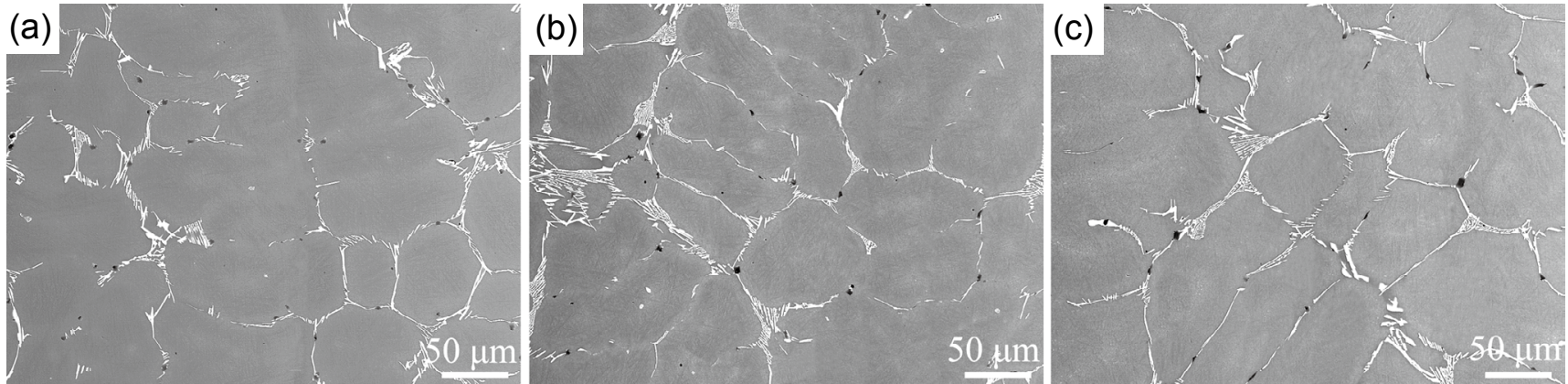

Fig. 6: Backscattered images of carbides distribution with melting rate of $2 \mathrm{~kg} \cdot \mathrm{min}^{-1}(\mathrm{a}), 1.2 \mathrm{~kg} \cdot \mathrm{min}^{-1}$ (b), and $0.8 \mathrm{~kg} \cdot \mathrm{min}^{-1}$ (c)
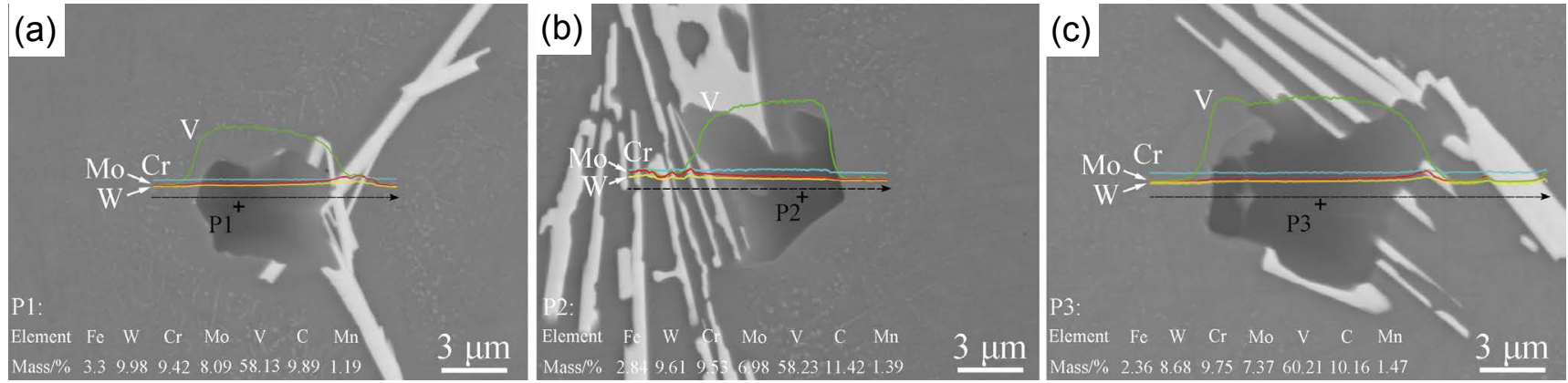

Fig. 7: Backscatter images of MC carbides under different melting rates of $2 \mathrm{~kg} \cdot \mathrm{min}^{-1}(\mathrm{a}), 1.2 \mathrm{~kg} \cdot \mathrm{min}^{-1}(\mathrm{~b})$, and $0.8 \mathrm{~kg} \cdot \mathrm{min}^{-1}(\mathrm{c})$

\subsection{Effect of melting rate on precipitation mechanism of primary MC carbide by thermodynamic calculation}

As known in Fig. 4, all the peaks of MC carbide are close to that of $\mathrm{VC}_{0.88}\left(\mathrm{a}_{0}=0.8334 \mathrm{~nm}\right)$. Therefore, in this study, $\mathrm{VC}_{0.88}$ was used to analyze the precipitation behavior of $\mathrm{MC}$ carbide. The precipitation of $\mathrm{VC}_{0.88}$ carbides is not only related to the standard Gibbs free energy $\left(\Delta G^{0}\right)$, but also to the content of $\mathrm{C}$ $([\% \mathrm{C}])$ and $\mathrm{V}([\% \mathrm{~V}])$. The reaction of $\mathrm{VC}_{0.88}$ in the molten steel is shown as follows ${ }^{[27]}$ :

$$
\begin{gathered}
{[\mathrm{V}]+0.88[\mathrm{C}]=\mathrm{VC}_{0.88}(\mathrm{~s}), \Delta G^{0}=-121,172+96.62 T} \\
\Delta G=\Delta G^{0}+R T \ln K_{\mathrm{VC}_{0.88}} \\
K_{\mathrm{VC}_{0.88}}=\frac{a_{\mathrm{VC}_{0.88}}}{a_{[\mathrm{V}]} a_{[\mathrm{C}]}^{0.88}}=\frac{1}{f_{\mathrm{V}}[\% \mathrm{~V}] f_{\mathrm{C}}^{0.88}[\% \mathrm{C}]^{0.88}}
\end{gathered}
$$

where $a_{\mathrm{VC}_{0.88}}$, the activity of $\mathrm{VC}_{0.88}$, can be considered as unified under present experimental conditions. $a_{[\mathrm{V}]}, a_{[\mathrm{C}]}$ are the Henrian activities of $\mathrm{V}$ and $\mathrm{C}$ relative to $1 \mathrm{mass} \%$ standard state in liquid iron, respectively, and $f_{\mathrm{V}}$ and $f_{\mathrm{C}}$ are the activity coefficients of $\mathrm{V}$ and $\mathrm{C}$, respectively. Their activity coefficients can be obtained using Wagner theory ${ }^{[28]}$ :

$$
\lg f_{\mathrm{C}}=\sum_{j=2}^{n} e_{\mathrm{C}}^{j}[\% j]
$$

$$
\lg f_{\mathrm{V}}=\sum_{j=2}^{n} e_{\mathrm{V}}^{j}[\% j]
$$

where $e_{\mathrm{C}}^{j}$ and $e_{\mathrm{V}}^{j}$ are the first-order interaction parameters of component $j$ on component $\mathrm{C}$ and $\mathrm{V}$, respectively. Since there is little data on second-order or high-order interaction parameters of these components, and the first-order interaction parameters can already meet the accuracy of thermodynamic calculation, the second-order or high-order interaction parameters are omitted in the calculation. The first-order coefficients in the molten steel at $1,873 \mathrm{~K}$ are listed in Table $2^{[29]}$.

In order to evaluate whether $\mathrm{VC}_{0.88}$ carbide is precipitated in the liquid, or mushy, or solid state, the liquidus and solidus temperatures need to be determined, according to Eqs. (9) ${ }^{[30]}$ and $(10)^{[21]}$. According to the alloy composition, the liquidus and solidus temperatures of $\mathrm{M} 2$ are $1,452{ }^{\circ} \mathrm{C}$ and $1,228^{\circ} \mathrm{C}$, respectively. Thus, based on the Eqs. (4)-(8), the Gibbs free energy $(\Delta G)$ of $\mathrm{VC}_{0.88}$ at the liquidus temperature is about $50.39 \mathrm{~kJ} \cdot \mathrm{mol}^{-1}$. It is much greater than 0 , which means that $\mathrm{VC}_{0.88}$ cannot be precipitated at the liquidus temperature.

$$
\begin{aligned}
T_{\mathrm{L}}= & 1,536-78[\% \mathrm{C}]-9[\% \mathrm{Si}]-5[\% \mathrm{Mn}]-1.8[\% \mathrm{Cr}] \\
& -0.2[\% \mathrm{~W}]-2[\% \mathrm{Mo}]-2[\% \mathrm{~V}]\left({ }^{\circ} \mathrm{C}\right) \\
T_{\mathrm{S}} & =1,266-110[\% \mathrm{C}]-3[\% \mathrm{Si}]+4[\% \mathrm{~W}]+2[\% \mathrm{Mo}] \\
& +10[\% \mathrm{~V}]+15[\% \mathrm{Nb}]\left({ }^{\circ} \mathrm{C}\right)
\end{aligned}
$$

Table 2: First-order interaction coefficients $e_{i}^{j}$ in molten steel at $1,873 \mathrm{~K}^{[29]}$

$\begin{array}{cccccccccc}\mathbf{e}_{i}^{j} & \mathbf{C} & \mathrm{Si} & \mathrm{Mn} & \mathbf{W} & \mathrm{Mo} & \mathrm{V} & \mathrm{Cr} & \mathrm{Al} \\ \mathrm{C} & 0.14 & 0.08 & -0.012 & -0.0056 & -0.0083 & -0.077 & -0.024 & 0.043 \\ \mathrm{~V} & -0.34 & 0.042 & & & & 0.015 & 0.012 & 0.1\end{array}$


When the temperature drops below the liquidus, solidification occurs and the solute elements are redistributed, and microsegregation is formed because of the insufficient diffusion of solute elements. To clarify the precipitation behavior of $\mathrm{VC}_{0.88}$, the segregation of $\mathrm{C}$ and $\mathrm{V}$ should be taken into account during the solidification process. On the one hand, though the diffusion coefficients of $\mathrm{C}$ in both $\delta$ phase and $\gamma$ phase are very high, the diffusion coefficient of $\mathrm{V}$ in $\delta$ phase is about 2-3 orders of magnitude higher than that in $\gamma$ phase, as shown in Fig. 3. The main factor that determines the $\mathrm{V}$ segregation is the diffusion speed of $\mathrm{V}$ in $\gamma$ phase, rather than the diffusion speed in $\delta$ phase. On the other hand, since the solidification takes place in the water-cooled copper mold during ESR process, the cooling rate is fast and the high-temperature $\delta$ phase stays for a relatively short time. Thus, in order to simplify the calculation, the precipitation of primary $\delta$ phase is ignored, and element redistribution only occurs between the $\gamma$ phase and the molten steel in the M2 alloy. In this study, the $\mathrm{C}-\mathrm{K}$ model ${ }^{[31]}$, which is a back-diffusion model, is used to calculate the element segregation. Its basic assumptions are ${ }^{[31]}$ : (i) there is complete diffusion in the liquid phase, (ii) there is a local equilibrium at the solid-liquid interface, (iii) the equilibrium partition coefficient of solute element and slope of the liquidus line are constant throughout solidification, (iv) the effects of nucleation undercooling and fluid-flow are negligible.

The C-K microsegregation model is as follows ${ }^{[26,31]}$ :

$$
C_{\mathrm{L}, i}=C_{0, i}\left[1+f_{\mathrm{S}}\left(\beta_{i} k_{i}-1\right)\right]^{\left(1-k_{i}\right) /\left(\beta_{i} k_{i}-1\right)}
$$

where $C_{\mathrm{L}, i}$ is the liquid concentration of a given solute element $i$ at the solid-liquid interface, $C_{0, i}$ is the initial liquid concentration of element $i . k_{i}$ is the equilibrium partition coefficient for element $i$. The value of $k_{i}$ between $\gamma$ phase and liquid phase is listed in Table 1. $f_{\mathrm{S}}$ is the solid fraction, and defined as follows:

$$
f_{\mathrm{S}}=\frac{T_{0}-T_{\mathrm{S}}}{T_{\mathrm{L}}-T_{\mathrm{S}}} \cdot \frac{T_{\mathrm{L}}-T}{T_{0}-T}
$$

where, $T$ is the temperature of the liquid phase during solidification, $T_{\mathrm{L}}$ and $T_{\mathrm{S}}$ are the liquidus and solidus temperature, respectively, and $T_{0}$ is the melting point of pure iron $\left(1,536{ }^{\circ} \mathrm{C}\right)$.

$\beta_{i}$ is a back-diffusion parameter of element $i$, and defined as follows:

$$
\beta_{i}=2 \alpha_{i}\left[1-\exp \left(-\frac{1}{\alpha_{i}}\right)\right]-\exp \left(-\frac{1}{2 \alpha_{i}}\right)
$$

where $\alpha_{i}$ is a Fourier number for solute element $i$, and defined as follows:

$$
\alpha_{i}=\frac{4 D_{i}^{\gamma} t_{\mathrm{f}}}{d_{\mathrm{II}}^{2}}
$$

where $D_{i}^{\gamma}$ is the diffusion coefficient of solute element $i$ in $\gamma$ phase, and the value of $D_{i}^{\gamma}$ is shown in Fig. 3. $d_{\mathrm{II}}$ is the SDAS. $t_{\mathrm{f}}$ is the LST, and could be calculated by Eq. (2).
Through Eqs. (11) and (14), the influence of the melting rate on the precipitation of $\mathrm{VC}_{0.88}$ during solidification can be illustrated as shown in Fig. 8. When the SDAS is lower than $70 \mu \mathrm{m}, \Delta G$ is already lower than 0 before the solid fraction $\left(f_{\mathrm{s}}\right)$ is equal to 1 . (When $f_{\mathrm{s}}=1$, it corresponds to the solidus temperature.) This means that $\mathrm{VC}_{0.88}$ can be precipitated in the final solidification stage. In this experiment, since the SDAS is no more than $70 \mu \mathrm{m}$, the large-sized MC carbides observed in Fig. 6 and Fig. 7 are all precipitated from the liquid during solidification. Furthermore, as the SDAS is decreased, the $\Delta G$ curve of $\mathrm{VC}_{0.88}$ tends to shift to the lower solid fraction (Fig. 8). It is inferred that $\mathrm{VC}_{0.88}$ can be formed at a higher temperature, or the thermodynamic driving force of $\mathrm{VC}_{0.88}$ precipitation can be enhanced at small SDAS. Therefore, the number of such MC carbides increases at the small SDAS caused by the high melting rate $\left(2 \mathrm{~kg} \cdot \mathrm{min}^{-1}\right.$ in this study), which is consistent with the experimental results of Fig. 4. Because that the SDAS at $2 \mathrm{~kg} \cdot \mathrm{min}^{-1}$ is the smallest, LST is the shortest according to Eq. (2), and there is not sufficient time to grow up for MC carbide. Therefore, the amount of MC carbides having the size greater than $8 \mu \mathrm{m}$ is significantly reduced at the melting rate of $2 \mathrm{~kg} \cdot \mathrm{min}^{-1}$.

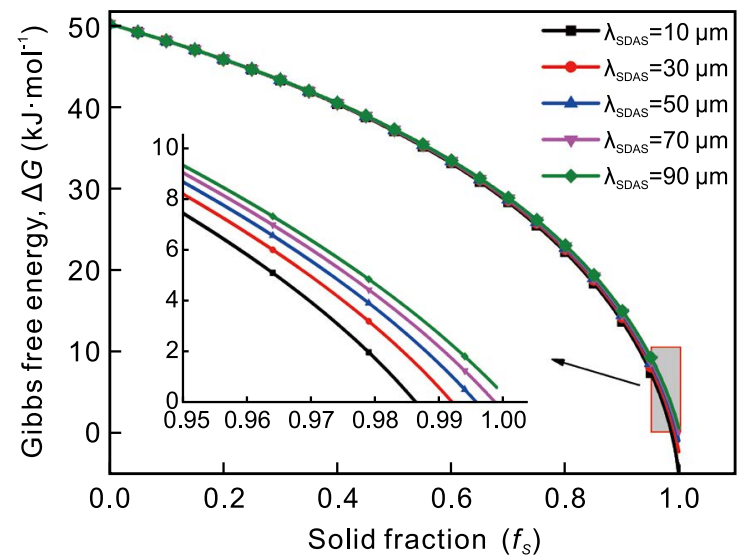

Fig. 8: Relationship between Gibbs free energy of $\mathrm{VC}_{0.88}$ and SDAS during solidification

\section{Conclusions}

(1) When the melting rate is decreased from $2 \mathrm{~kg} \cdot \mathrm{min}^{-1}$ to $0.8 \mathrm{~kg} \cdot \mathrm{min}^{-1}$, the columnar dendrites are gradually coarsened. At the melting rate of $2 \mathrm{~kg} \cdot \mathrm{min}^{-1}$, the extent of segregation of $\mathrm{Mo}$ and $\mathrm{Cr}$ is relatively large, and segregation of $\mathrm{W}$ is the smallest. As the melting rate gradually decreases to $0.8 \mathrm{~kg} \cdot \mathrm{min}^{-1}$, the segregation of Mo and $\mathrm{V}$ tends to be alleviated, while the segregation of $\mathrm{Cr}$ becomes severe. There is little change in the segregation of $\mathrm{W}$.

(2) The number of primary MC carbides per unit area with the sizes in the range of $2 \mu \mathrm{m}$ to $6 \mu \mathrm{m}$ accounts for about $75 \%$ of all $\mathrm{MC}$ carbides at $2 \mathrm{~kg} \cdot \mathrm{min}^{-1}$, while the carbides are mainly concentrated on the size larger than $8 \mu \mathrm{m}$ at $0.8 \mathrm{~kg} \cdot \mathrm{min}^{-1}$. As the melting rate is reduced from $2 \mathrm{~kg} \cdot \mathrm{min}^{-1}$ to $0.8 \mathrm{~kg} \cdot \mathrm{min}^{-1}$, the size of carbides with the greatest number per unit area is gradually increased, the number of carbides is decreased. 
(3) As calculated by C-K model, MC carbide can be precipitated in the final solidification stage. A smaller secondary dendrite arm spacing caused by the higher melting rate $\left(2 \mathrm{~kg} \cdot \mathrm{min}^{-1}\right.$ in the experiment $)$ helps refinement of the primary MC carbide.

\section{Acknowledgements}

This work was financially supported by the National Natural Science Foundation of China (No. 51904087), the Open Project of State Key Laboratory of Advanced Special Steel, Shanghai Key Laboratory of Advanced Ferrometallurgy, Shanghai University (SKLASS 2019-20) and the Science and Technology Commission of Shanghai Municipality (No. 19DZ2270200), the Natural Science Foundation-Steel and Iron Foundation of Hebei Province (No. E2019202482), and Tianjin Science and Technology Project (No. 18YFZCGX00220).

\section{References}

[1] Boccalini M, Goldenstein H. Solidification of high speed steels. International Materials Reviews. 2001, 46(2): 92-115.

[2] Wang H B, Hou L G, Ou P, et al. Enhanced microstructures and properties of spray-formed M3:2 high-speed steels by niobium addition and thermal-mechanical treatment. Journal of Materials Research, 2018, 34(6): 1043-1053.

[3] Ding P D, Shi G Q, Zhou S Z. As-cast carbides in high-speed steels. Metallurgical \& Materials Transactions A, 1993, 24A: 1265-1272.

[4] Chaus A S, Sahul M. On origin of delta eutectoid carbide in M2 high-speed steel and its behaviour at high temperature. Materials Letters, 2019, 256: 126605.

[5] Luo Y W, Guo H J, Sun X L, et al. Gleeble-simulated and semiindustrial studies on the microstructure evolution of $\mathrm{Fe}-\mathrm{Co}-\mathrm{Cr}$ Mo-W-V-C alloy during hot deformation. Materials, 2018, 1: 326-322.

[6] Pan F S, Wang W Q, Tang A T, et al. Phase transformation refinement of coarse primary carbides in M2 high speed steel. Progress in Natural Science: Materials International, 2011, 21: 180-186.

[7] Guo G S. High speed steel and its heat treatment. Beijing: Industry Press, 1985: 97. (In Chinese)

[8] Hwang K C, Lee S, Lee H C. Effects of alloying elements on microstructure and fracture properties of cast high speed steel rolls, Part II: Fracture behavior. Materials Science and Engineering: A, 1998, 254(1-2): 296-304.

[9] Bombač $D$, Terčelj $M$, Fazarinc $M$, et al. On the increase of intrinsic workability and hot working temperature range of M42 ledeburitic super high steel in as-cast and wrought states. Materials Science and Engineering: A, 2017, 703: 438-450.

[10] Ghomashchi M R, Sellars C M. Microstructural changes in as-cast M2 grade high speed steel during hot forging. Metallurgical Transactions, A (Physical Metallurgy and Materials Science), 1993, 24A: 2171-2180.

[11] Dobrzański L A, Zarychta A, Ligarski M. High-speed steels with addition of niobium or titanium. Journal of Materials Processing Technology, 1997, 63(1-3): 531-541.

[12] Dobrzański L A, Zarychta A, Ligarski M. Phase transformations during heat treatment of W-Mo-V 11-2-2 type high-speed steels with increased contents of $\mathrm{Si}$ and $\mathrm{Nb}$ or Ti. Journal of Materials Processing Technology, 1995, 53(1-2): 109-120.
[13] Li Y J, Jiang Q C, Zhao Y G, et al. Improvement of the microstructure and mechanical properties of M2 cast high speed steel by modification. Journal of Materials Science Letters, 1996, 15(18): 1584-1586.

[14] Fu H G, Du J M, Jiang Z Q, et al. Effect of RE-Al-N on structures and properties of M2 cast high speed steel. Journal of Rare Earths, 2003, 21(6): 664-668.

[15] Zhou X F, Zhu W L, Jiang H B, et al. A new approach for refining carbide dimensions in M42 super hard high-speed steel. Journal of Iron and Steel Research, International, 2016, 23(8): 800-807.

[16] Zhou X F, Fang F, Jiang J Q, et al. Refining carbide dimensions in AISI M2 high speed steel by increasing solidification rates and spheroidising heat treatment. Materials Science \& Technology, 2014, 30(1): 116-122.

[17] Luan Y K, Song N N, Bai Y L, et al. Effect of solidification rate on the morphology and distribution of eutectic carbides in centrifugal casting high-speed steel rolls. Journal of Materials Processing Technology, 2010, 210(3): 536-541.

[18] Li Z B. Electroslag metallurgy theory and practice. Beijing: Metallurgical Industry Press, 2011: 66. (In Chinese)

[19] Chen X, Jiang Z H, Liu F B, et al. Effect of melt rate on surface quality and solidification structure of $\mathrm{Mn} 18 \mathrm{Cr} 18 \mathrm{~N}$ hollow ingot during electroslag remelting process. Steel Research International, 2017, 88(2): 188-196.

[20] Zhu Q T, Li J, Zhang J, et al. Precipitation mechanism and reduction of amount of primary carbides during electroslag remelting of $8 \mathrm{Cr} 13 \mathrm{MoV}$ stainless steel. Metallurgical and Materials Transactions B, 2019, 50B: 1365-1377.

[21] Fischmeister H F, Riedl R, Karagöz S. Solidification of highspeed tool steels. Metallurgical \& Materials Transactions A, 1989, 20(10): 2133-2148.

[22] Mitchell A, Smailer R M. Practical aspects of electroslag remelting technology. International Metals Reviews, 1979, 5(6): 231-264.

[23] Hernandez-Morales B, Mitchell A. Review of mathematical models of fluid flow, heat transfer, and mass transfer in electroslag remelting process. Ironmaking \& Steelmaking, 1999, 26(6): 423-438.

[24] Huang $Y$ W, Long $M$ J, Liu $P$, et al. Effects of partition coefficients, diffusion coefficients, and solidification paths on microsegregation in Fe-Based multinary alloy. Metallurgical \& Materials Transactions B, 2017, 48(5): 2504-2515.

[25] Fredriksson $H$. The mechanism of the peritectic reaction in iron-base alloys. Metal Science, 1976, 10(3): 77-86.

[26] Choudhary S K, Ghosh A. Mathematical model for prediction of composition of inclusions formed during solidification of liquid Steel. ISIJ International, 2009, 49(12): 1819-1827.

[27] Sun X L, Guo H J, Chen X C, et al. Formation mechanism of primary carbide in $\mathrm{H} 13$ steel during electroslag remelting process. Iron and Steel, 2014, 49(5): 68-73. (In Chinese)

[28] Huang $X \mathrm{H}$. Principle of iron and steel metallurgy. Beijing: Metallurgical Industry Press, 1990: 52. (In Chinese)

[29] Chen J X. Date manual for charts and graphs commonly used in steelmaking, 2nd ed. Beijing: Metallurgical Industry Press, 2010: 758. (In Chinese)

[30] Zhao Z G. Basic research on continuous casting process of high speed steel. Doctoral dissertation, Beijing: University of Science and Technology Beijing, 2018. (In Chinese)

[31] Clyne T W, Kurz W. Solute redistribution during solidification with rapid solid state diffusion. Metallurgical Transactions A, 1981, 12(6): 965-971. 